\title{
Expert Assessments of Retrofitting Coal-fired Power Plants with Carbon Dioxide Capture Technologies
}

\author{
Timothy S. Chung \\ Dr. Dalia Patino-Echeverri, Advisor \\ May 2009
}

Masters Project submitted in partial fulfillment of the requirements for the

Master of Environmental Management degree in the Nicholas School of the Environment of Duke University 2009 


\begin{abstract}
Carbon dioxide capture and storage is an emerging set of technologies that can contribute to significant reductions in $\mathrm{CO}_{2}$ emissions. However, a substantial amount of uncertainty belies the technical and economic feasibility of capturing $\mathrm{CO}_{2}$ at commercial scale. This study explores the uncertainties associated with carbon dioxide capture technologies, with a specific focus on retrofitting existing coal-fired power plants. 13 respondents with expertise in postcombustion and oxy-fuel combustion capture systems responded to an extensive questionnaire and provided their opinions on present status and future expected performance and costs for amine-based systems, chilled ammonia process, and oxy-combustion.

Expert elicitation, a formal protocol for obtaining probabilistic judgments on a subject with insufficient data, was the primary method used to establish best estimates and $95 \%$ confidence limits of the energy penalties associated with the technologies under focus. Additionally, this paper presents observations based on the aggregated responses for technology maturity, ideal plant characteristics for early adopters, and the extent to which R\&D and deployment incentives will impact costs.

The results show a general consensus that amine-based systems are closer to commercial application, but potential for improving performance and lowering costs is limited; chilled ammonia and oxy-combustion contain greater potential for cost reductions, but not without greater uncertainty in regard to scale and technical feasibility.

A cost model using expert estimates of expected energy penalties was developed to establish 2030 projections of $\mathrm{CO}_{2}$ capture costs for amine-based systems. Results from the model indicate that under the reference case (current trends in RD\&D), the energy penalty reduction equates to an $11 \%$ decrease in annual energy costs. In the best case scenario (best results under an enhanced RD\&D policy), the annual energy savings are $29 \%$ and the $\mathrm{CO}_{2}$ capture cost decreases $16 \%$ from $\$ 55$ (in the reference case) to $\$ 46$ per ton of $\mathrm{CO}_{2}(2006$ dollars).
\end{abstract}




\section{Acknowledgments}

I thank the participating experts in Table I. Nick Hutson and Marty Lail piloted the elicitation and provided valuable feedback. Tim Johnson (US EPA) provided many hours of guidance and his input on the survey design was critical for the completion of this study. Eric Williams (Climate Change Policy Partnership, Duke University) helped a great deal with the development of the cost model. I am especially grateful to Dalia Patino-Echeverri (Duke University) for her endless generosity and patience in advising this project and seeing it through to its completion.

Thanks to Jane for making space for my stress. Finally, I am indebted to my parents and my brother who have supported me unconditionally in all of my life's pursuits. Your love has always been sufficient.

Table I: The thirteen experts who participated in this study

\begin{tabular}{|l|l|}
\hline \multicolumn{1}{|c|}{ Name } & \multicolumn{1}{c|}{ Affiliation } \\
\hline Dan Duellman & American Electric Power \\
Tom Nelson & Research Triangle Institute \\
\hline Stuart Dalton & Electric Power Research Institute \\
Richard Winschel & Consol Energy \\
Ravi Srivastava & Environmental Protection Agency \\
Raghubir Gupta & Research Triangle Institute \\
Nick Irvin & Southern Company \\
Mike Hammond & American Electric Power \\
Luke Coleman & Research Triangle Institute \\
John Wootten & Peabody Energy \\
Glen Jukkola & Alstom \\
Gary Spitznogle & American Electric Power \\
Chen Chao & Warley-Parsons \\
\hline
\end{tabular}




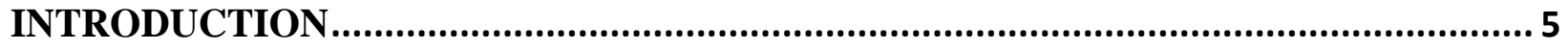

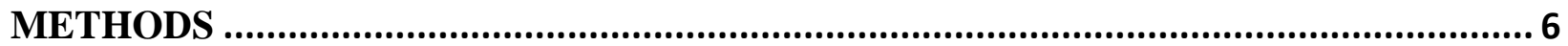

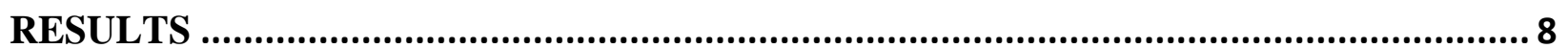

Maturity of $\mathrm{CO}_{2}$ Capture Systems ……..................................................................................

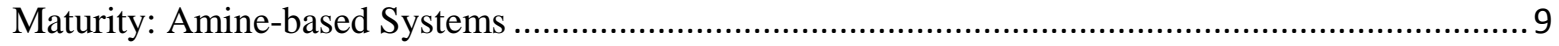

Maturity: Chilled Ammonia Process ............................................................................................ 10

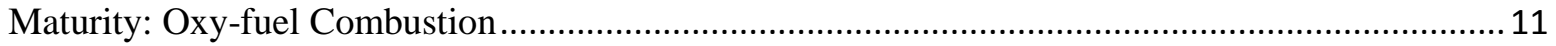

IDEAL PLANT CHARACTERISTICS ................................................................................

IDENTIFYING POTENTIAL TRENDS IN CAPITAL AND O\&M COSTS ...............................16

PROBABILISTIC JUDGMENTS ON PARASITIC LOAD .....................................................23

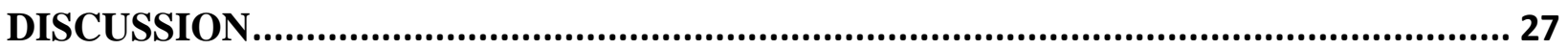

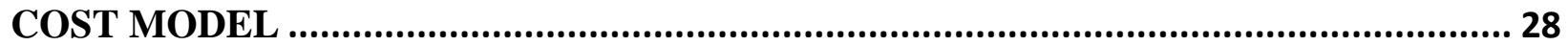

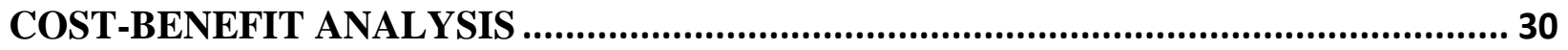

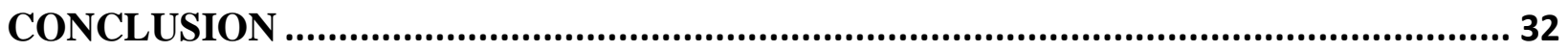

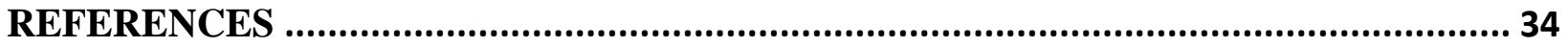




\section{INTRODUCTION}

There is wide spread recognition that anthropogenic emissions of carbon dioxide $\left(\mathrm{CO}_{2}\right)$ are contributing to global climate change. One of the difficulties in addressing this issue is that the major source of human caused $\mathrm{CO}_{2}$ emissions is also a major source of electricity generation: coal-fired power plants. Reductions of $\mathrm{CO}_{2}$ emissions from the combustion of fossil fuels are needed to avoid dangerous levels of greenhouse gas concentrations in the atmosphere. At the same time, demand for electricity is increasing and coal is expected to remain a dominant fuel for electricity generation through 2030 (EIA, 2008).

Carbon capture and sequestration $(\mathrm{CCS})$ - a process that isolates $\mathrm{CO}_{2}$ from the atmosphere through long term geological storage - is a mitigating option that addresses this conundrum. CCS can significantly reduce the amount of $\mathrm{CO}_{2}$ emitted from coal-fired power plants while enabling their operation until less carbon intensive sources of energy can bear more of the load. The integrated process of CCS includes the capture and compression of CO2 to high pressures, transportation to a storage site, and injection into a suitable geologic reservoir. Each step is capital and energy intensive, with a great amount of uncertainty surrounding the performance and costs of installing and operating a CCS facility at commercial scale.

This study aims to narrow the window of uncertainties associated with retrofitting pulverized coal-fired power plants with three CO2 capture systems: amine-based systems, chilled ammonia process, and oxy-fuel combustion. The objective of this paper is to identify potential improvements in capture technologies and to quantify expert assessments of the current status and future expected costs and performance of $\mathrm{CO}_{2}$ capture and compression. 
Retrofits are of particular interest because most studies to date focus on costs and performance of new CCS plants. Studies that do focus on retrofits have been limited to aminebased applications since data is available and amines are familiar to the industry. One concern with new CCS units is that they only reduce $\mathrm{CO} 2$ emissions growth, unless they actually replace older units that generate the same product (Simbeck, 2007). But even assuming that new units would effectively enable the retirement of existing units, permitting new sites is becoming increasingly difficult and only 12 units have been constructed since 1990 (Pew, 2009). The more pressing concern is that the current fleet of coal-fired power plants is aging, evidenced by the average boiler age of 42 years (EPA, 2007). With over 320 GW of U.S. coal-fired electricity generation capacity, there are significant abatement opportunities from older vintage units that have been operating for many decades. Moreover, the EIA Annual Energy Outlook 2009 projects only $2.3 \mathrm{GW}$ of existing coal capacity retirements by 2030 (EIA, 2009). CCS retrofits and major brown-field repowering will be necessary to curb $\mathrm{CO} 2$ emissions from the electricity sector.

\section{METHODS}

Drawing from a previously developed protocol of formally eliciting expert assessments on technologies (Curtright, 2008), I obtained expert opinions on present status and future probabilistic judgments of CCS retrofit costs and performance for amine-based systems, chilled ammonia processes, and oxy-fuel combustion. Initially, I elicited responses for parasitic load, costs per metric ton of $\mathrm{CO} 2$ avoided, and future expected decreases in capital and O\&M costs. The pilot interviews and initial formal interviews revealed that not all experts were familiar with these cost parameters, which limited the scope of this study to obtaining probabilistic judgments 
on parasitic load alone. Some experts nonetheless offered their judgments on $\mathrm{CO}_{2}$ avoided costs and expected percentage decreases for capital and O\&M component costs, but these numbers are not reported because too few responses were obtained.

I targeted engineers with applied technical experience working with $\mathrm{CO}_{2}$ capture technologies. Thirteen experts (seven from industry and six from research institutions) with various areas of expertise with respect to post-combustion and oxy-combustion retrofit technologies participated via telephone and face-to-face interviews. Each participant was interviewed for approximately one hour, responding to the following issues: 1) the present status and maturity of the $\mathrm{CO}_{2}$ capture systems with respect to application on coal-fired power plants; 2) the plant specifications necessary for an ideal early adopter retrofit; 3) the future expected cost trends for capital and O\&M components in 2030 under four R\&D and deployment scenarios; and 4) the future expected energy penalty incurred by a retrofitted plant in 2030.

The survey was mailed electronically prior to the interviews, and the responses were documented during the interview. All responses are reported anonymously. The interviews were conducted during the months of December 2008 and January 2009. Table 1 reports the participants' relative level of expertise in post-combustion and oxy-combustion technologies.

\begin{tabular}{|l|c|c|c|c|c|c|c|c|c|c|c|c|c|}
\hline & Expert 1 & Expert 2 & Expert 3 & Expert 4 & Expert 5 & Expert 6 & Expert 7 & Expert 8 & Expert 9 & Expert 10 & Expert 11 & Expert 12 & Expert 13 \\
\hline Amines & 4 & 6 & 3 & 7 & 5 & 4 & 2.5 & 4.5 & 2 & 4.5 & 4.5 & 7 & 3 \\
Chilled Ammonia & 6 & 6 & 3 & 7 & 6 & 3 & 2.5 & 4.5 & 2 & 3.5 & 3.5 & 6.5 & 3 \\
\hline Oxyfuel & 5 & 4 & 5 & 6 & 5 & 3 & 2.5 & 3.5 & 3 & 6.5 & 3.5 & 5.5 & 4 \\
\hline
\end{tabular}

Table 1.Experts' level of familiarity with technologies. Scale ranges from 1 to 8 : $1=$ "Only general knowledge of this technology" $8=$ "Among the few top experts in this technology" 


\section{RESULTS}

\section{Maturity of $\mathrm{CO}_{2}$ Capture Systems}

Using a scale of 1 to $8(1=$ "Not mature: significant room for improvement," and $8=$

"Very mature: very little room for improvement"), the experts were asked to provide their opinions of the maturity of each technology with respect to capturing $\mathrm{CO} 2$ from coal-fired commercial-scale power plants. The scale captures expert judgments about the overall relative maturity of each system and is accordingly not representative of the absolute maturity of the $\mathrm{CO}_{2}$ capture systems.

The purpose of this section is to highlight recurring issues that emerged concerning the current status of these technologies. Figure 1 depicts the range of expert opinions on the maturity level of each capture system. With a median level of 6 established for amines, compared to a median of 3 for both chilled ammonia and oxy-combustion, the responses show a strong consensus that amine systems are currently closer to commercial application than chilled ammonia or oxy-fuel. However, Experts 4 and 13 preferred to bifurcate amines into two groups (MEA and advanced amines) to express their opinions of the relative immaturity of advanced amines; their responses for advanced amines were 2.5 and 3 levels of magnitude lower than MEA on the scale of 1 to 8 , respectively.

\begin{tabular}{|c|c|c|c|c|c|c|c|c|c|c|c|c|c|}
\hline & Expert 1 & Expert 2 & Expert 3 & Expert 4 & Expert 5 & Expert 6 & Expert 7 & Expert 8 & Expert 9 & Expert 10 & Expert 11 & \begin{tabular}{|l|} 
Expert 12 \\
\end{tabular} & Expert 13 \\
\hline Amines & 6 & 8 & 7 & 7 & 5 & 6 & 2.5 & 6 & 3.5 & 5 & 7 & 5 & 6.5 \\
\hline Chilled Ammonia & 4 & 3 & 1.5 & 7 & 2 & 4 & 2.5 & 4 & 1.5 & 2 & 4 & 2 & 4 \\
\hline Oxyfuel & 4 & 3 & 2.5 & 4.5 & 2 & 3 & 1.5 & 6 & 1.5 & 4 & 7.5 & 2 & 4 \\
\hline
\end{tabular}

Table 2. Expert judgments about the level of maturity of CO2 capture systems with respect to coal-fired power plant application. Scale ranges from 1 to 8: 1 = "Not mature: significant room for improvement" 8 = "Very mature: very little room for improvement" 


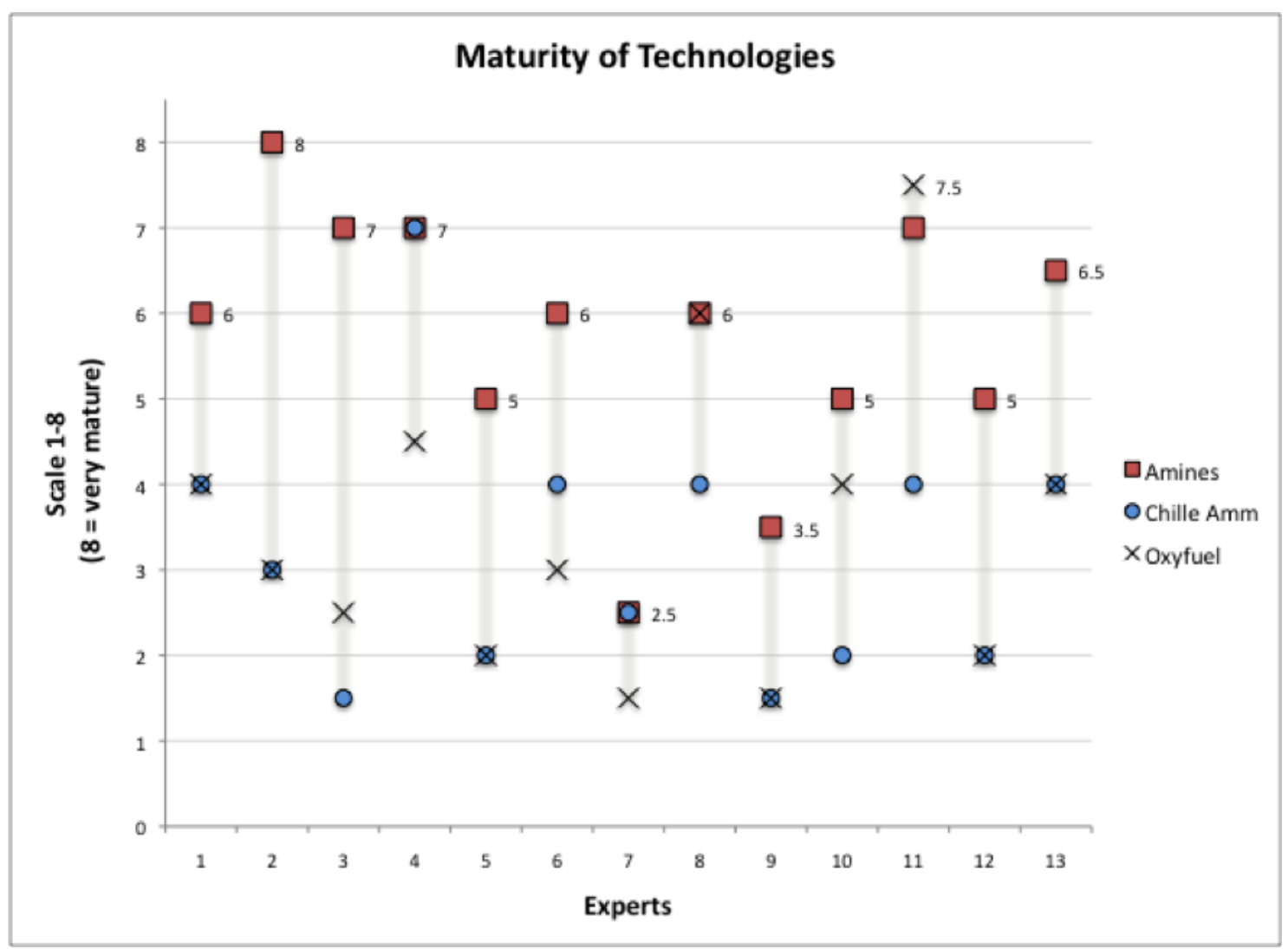

Figure 1. Expert judgments about the level of maturity of $\mathrm{CO} 2$ capture systems with respect to coalfired power plant application. Scale ranges from 1 to 8:

1 = "Not mature: significant room for improvement"

8 = "Very mature: very little room for improvement".

\section{Maturity: Amine-based Systems}

Nine of the thirteen experts considered amine-based capture systems the most mature technology relative to chilled ammonia and oxy-fuel combustion. Two experts, for separate reasons, believed that amines and chilled ammonia are equal in maturity level: expert 4 is the exception in his perception that chilled ammonia is well understood and has little room for improvement, while expert 7 noted that amine sorbents still need significant improvement to lower regeneration requirements. Experts 8 and 11 considered oxy-fuel at or above the level of maturity of amines, stating that oxy-coal is a well known process that only needs improvements in boiler modification and design. 
In general, the experts attribute the advanced maturity level of amines to the industry's long familiarity with using amines for a variety of commercial applications, including urea production and food processing (Anderson \& Newell, 2004). Even the responses at the lower end of the range are not attributable to potential learning or experience with the chemical processes of capturing $\mathrm{CO}_{2}$, but the scale at which it needs to be operated for coal-fired power plants. The overarching concern with amine-based systems is scale. Though relatively large slipstream demonstrations are already in operation, there is considerable concern that aminebased capture systems are still several hurdles from commercial scale operation. In the words of one expert, "You can buy it and force it to work, but it still doesn't have a track record of success. It still needs demonstration.” Studies agree that considerable scale-up is necessary before any post-combustion technologies can be implemented on PC units cost-effectively (National Coal Council, 2007). Noted issues with scaling up amine systems include integrating extremely large modules and achieving better steam integration. Two experts disagreed with the concern of scale, noting that the industry already operates large modules for amine systems and that efficient steam use and improved corrosion inhibitors present greater challenges.

\section{Maturity: Chilled Ammonia Process}

The chilled ammonia process is only recently removed from laboratory testing and its relative immaturity compared to amines is indicated by the experts' responses, which are almost unanimously clustered at the lower end of the scale (median value of 3). The common concerns with chilled ammonia are the lack of experience with the process and the limited scale at which it has been operated. At the time this paper was written, only a 1.2-MW pilot test at Pleasant Prairie Power Plant in Wisconsin, launched in mid-2008, constituted the extent of industry experience capturing CO2 with chilled ammonia (EPRI, 2008). To provide perspective, one expert candidly stated: "chilled ammonia has less than 1 year of operating experience on a coal- 
fired plant...for a grand total of 8000 hours of operating experience. Amines have 8000 hours of operating experience multiplied by 30 to 40 years. From that point of view, the level of experience on the chilled ammonia process is in its infancy." Other concerns surrounding chilled ammonia include ammonia slip and leakage risks, which could pose considerable health risks to populations within close proximity. One expert warned that power plant owners may be apprehensive about handling and storing a large amount of ammonia, noting that much more ammonia will be required for $\mathrm{CO} 2$ capture than is currently used in Selective Catalytic Reduction for NOx control (for an overview of controlling ammonia in SCR operations, see Krocher, 2007). The experts generally share optimism in chilled ammonia's potential to significantly reduce the energy penalty compared to amines, but concerns still arise with respect to the chemical process, integration and the current scarcity of data. One expert, suspicious of chilled ammonia's potential, complained that reports remain vague on the heating requirements for processes unique to chilled ammonia (the example he provided was the energy needed to heat the flue gas stream through the stack after it is chilled and washed).

Judging from Figure 1, no consensus is observable when comparing the maturity level of chilled ammonia to oxy-fuel. 6 respondents rate them with equal maturity, 4 experts consider oxy-fuel more advanced, and 3 experts consider chilled ammonia more advanced. According to one expert, research and deployment of chilled ammonia systems will likely advance more rapidly because it can be conducted using a slipstream, whereas oxy-fuel combustion requires testing on the entire boiler.

\section{Maturity: Oxy-fuel Combustion}

While the issues related to amines and chilled ammonia apply to the back-end of the combustion process, oxy-fuel combustion for retrofits presents a different set of issues due to 
modifying the combustion process itself. Contrary to optimistic views of expert 8 and 11, most studies categorize oxy-fuel as an emerging technology that requires much further research and development to become established (NCC, 2007). The predominant concerns with oxycombustion include boiler redesign, the air separation unit (ASU), the gas processing unit, the temperature profile in the boiler, flue gas recirculation and clean-up, air-in leakage, and scale. Most of the experts agree that conventional means of oxygen separation is too expensive, suggesting a breakthrough in ASU technology (namely, ion transport and oxygen transport membranes) is necessary to render oxy-combustion competitive for $\mathrm{CO}_{2}$ capture on pulverized coal power plants. However, experts 8 and 11 assert that it is competitive even without improvements in air separation technology. In their opinion, the capital and O\&M costs associated with the ASU are significant but not a dominant fraction of the costs associated with combustion redesign. Expert 8 argues that potential capital and O\&M cost reductions on the ASU are at most $10 \%$ each, even assuming integration with membrane technologies. This view, however, is inconsistent with at least one Praxair study that asserts its OTM boiler technology has the potential to reduce power consumed in air separation by greater than $75 \%$ (Hassel, Bart A., et al., 2008). The marginal impacts of a breakthrough in air separation technology are also contrary to the majority view of the experts sampled in this study. Four of the respondents specifically stated that oxy-combustion for $\mathrm{CO}_{2}$ capture will not move forward without improvements in the ASU. As one expert put it: "with no breakthrough there, it may never be economical to build oxy-fuel plants.”

Modifying an existing boiler for oxy-combustion could pose significant challenges. The current fleet of pulverized coal plants is designed for conventional combustion processes with air and coal, and some experts see problems concerning heat transfer and reconfiguring the boiler to 
handle the higher temperature profile and the different mass flow characteristics corresponding to oxygen and re-circulated $\mathrm{CO} 2$. One expert contends that these are minor modifications compared to installing a flue gas recirculation system, which may require replacing air ducts and fans (IEA, 2007). Another expert agreed, noting that the piping involved with recycling flue gas to the front end of the combustor would be a "nightmare" for existing units. This expert also raised concern about optimizing downstream gas clean-up under conditions of higher effluent concentrations. Though higher concentrations ease the process of gas clean-up in terms of percentage removal, complications may arise in terms of the amount of impurities entering the $\mathrm{CO}_{2}$ capture system. Achieving the acceptable volume of effluent may become increasingly difficult with higher effluent concentrations. Cost savings from reduced equipment size may negate this challenge, but the expert quickly points out that "we have to practice and see how it works out. We haven't operated a plant that way so we don't really know yet."

The magnitude of the issues facing oxy-combustion may depend on site-specific parameters like boiler age and efficiency. For example, some experts mentioned issues regarding air-in leakage for older vintage boilers, which would increase costs for a system designed for oxygen-combustion. Due to the lack of standardization in boiler designs in the United States, there may not be a standard retrofit design for oxy-combustion capture systems. One expert identified the greatest uncertainty surrounding oxy-combustion is the type of redesign the combustor will need. Thus, site-specific challenges have raised doubts about oxycombustion's suitability as a retrofit application. Although it is typically cited in literature as a candidate for retrofits (EPRI, 2008), several experts disagree, opining that the technology is more practical for new units or for a total rebuild. They argue that modifying the boiler, which constitutes a large portion of the plant, may give grounds for rebuilding the entire unit itself. The 
issue then becomes how one defines a "retrofit." If retrofits include major repowering on brownfield sites, then oxy-combustion remains an option.

\section{IDEAL PLANT CHARACTERISTICS}

The International Panel on Climate Control identified a set of site-specific parameters that must be considered for retrofitting coal-fired power plants with CCS technologies (IPCC, 2005):

- Space availability for capture equipment

- A long remaining plant life to justify CCS investment

- Newer plants with relatively higher energy efficiencies

Additionally, the Electric Power Research Institute extends the list to include issues related to (EPRI, 2008):

- Limited heat availability for process integration

- Limitation of the existing steam turbine

- Cooling water limitations

- Replacement power considerations

- Complicated pipe routings.

Assuming a $90 \% \mathrm{CO}_{2}$ removal rate, I asked the experts to provide their opinions of the most important characteristics the first 10 retrofitted pulverized coal-fired power plants will likely share in common. I did not provide a list of items but rather asked each expert to generate his own list containing at least three responses. Figure 2 represents the spectrum of collected responses. Space availability and location appear most frequently, with high efficient control technologies, age of the unit, and size also receiving considerable attention. 


\begin{tabular}{|c|c|c|c|c|c|c|c|c|}
\hline & $\begin{array}{c}\text { Land/Space } \\
\text { availability }\end{array}$ & Location & $\begin{array}{c}\text { State of art } \\
\text { control tech } \\
(\mathrm{FGD}, \mathrm{SCR}, \mathrm{PM})\end{array}$ & Age & Size & $\begin{array}{c}\text { Steam } \\
\text { availability }\end{array}$ & Water & $\begin{array}{c}\text { Public } \\
\text { utilities }\end{array}$ \\
\hline Expert 1 & $x$ & & $\mathrm{x}$ & $x$ & & & & \\
\hline Expert 2 & $x$ & $x$ & & & $\mathrm{x}$ & & & \\
\hline Expert 3 & $x$ & & $x$ & $x$ & & & & \\
\hline Expert 4 & $x$ & $x$ & $x$ & & & $x$ & & \\
\hline Expert 5 & $x$ & $x$ & $x$ & $x$ & & & & \\
\hline Expert 6 & & $x$ & & $x$ & $\mathrm{x}$ & & & \\
\hline Expert 7 & $x$ & $x$ & & $\mathrm{x}$ & $\mathrm{x}$ & & & \\
\hline Expert 8 & $\mathrm{x}$ & $\mathrm{x}$ & & & & $\mathrm{x}$ & $\mathrm{x}$ & \\
\hline Expert 9 & $x$ & $x$ & $x$ & $x$ & $x$ & & & $x$ \\
\hline Expert 10 & $\mathrm{x}$ & $\mathrm{x}$ & & $x$ & & & & \\
\hline Expert 11 & $x$ & $x$ & $x$ & & & & & \\
\hline Expert 12 & $\mathrm{x}$ & $\mathrm{x}$ & $x$ & $x$ & & & & \\
\hline Expert 13 & $x$ & $\mathrm{x}$ & $\mathrm{x}$ & & & $\mathrm{x}$ & & \\
\hline Frequency & 12 & 11 & 8 & 8 & 4 & 3 & 1 & \\
\hline
\end{tabular}

Figure 2. Expert responses for site-specific parameters necessary for retrofit

Some experts escalated the prerequisite of space availability with statements concerning the particular location of unoccupied space. Plants with space in close proximity to the Flue Gas Desulphurization (FGD) unit and the stack will have the advantage of minimizing gas duct runs. Finding the convenient space may be extremely difficult, however, since the necessary control technologies for effluents like $\mathrm{SO}_{2}$, $\mathrm{NOx}$, and particulate matter already occupy significant areas. One expert notes that the footprint of a $\mathrm{CO}_{2}$ capture plant could be up to $50 \%$ of the area of the original power plant. Another expert warns of the severity of this issue: "This is a larger retrofit process than anything we've ever seen before."

The location of power plants will determine their suitability for retrofit for several reasons. All eleven experts who mentioned location had in mind proximity to sequestration sites, enhanced oil recovery sites (EOR), or a pipeline network. One expert in particular asserts that the first 10 plants to retrofit will certainly utilize the benefits of EOR. Other factors contributing to the issue of locality include cooler climates, remote areas, and regional characteristics of fuel and power markets. Retrofits with chilled ammonia systems should benefit from cooler ambient temperature conditions like those found in the northern regions of the U.S. and Europe. Free access to cold water would reduce the power required to chill the flue gas, which is a process 
particularly necessary for chilled ammonia (Black, 2008). Two experts mentioned that remote areas will be important for first generation retrofit units in order to minimize risks to civilians; this concerns chilled ammonia systems in particular because a retrofitted unit would require a large captive volume of ammonia to maintain the process. One expert added that early adopters will favor market conditions characterized by the combination of low coal costs and high retail electricity prices.

The need for highly efficient control technologies to set the temperature of the flue gas and to reduce the concentration of contaminants entering the absorber vessel was also common concern. Some experts specified that state of the art wet FGD units for $\mathrm{SO}_{2}$ control would reap concurrent benefits that include reducing the cooling requirement of the flue gas. This is also noted in the IPCC Special Report on CCS, but the benefits have not been quantified. Eight experts stated that the age of power plants will strongly influence decisions concerning retrofits;

they agreed that modern units built within the last 20 to 25 years with higher efficiencies and relatively long remaining operating lives are most desirable for retrofits. This criterion may establish modern high efficiency super critical steam systems as the best candidates for early adopters. Additionally, several experts considered size an important factor: three agree that larger units (500MW or more) are optimal for achieving benefits from economies of scale, while one expert asserts that early adopters will begin retrofitting intermediate units between 350600MW to develop learning and experience before scaling up to larger units.

\section{IDENTIFYING POTENTIAL TRENDS IN CAPITAL AND O\&M COSTS}

To gain insight on the current state and potential cost reductions of commercial scale capital and O\&M components associated with $\mathrm{CO}_{2}$ capture systems, I asked the experts to 
provide judgments about the level of cost reductions achievable by 2030 according to 4 different policy scenarios (Curtright, 2008):

a) Current trend: current levels of global R\&D funding + current levels of deployment incentives of CCS technologies in general

b) Enhanced R\&D: 10 times current levels of global R\&D funding + current levels of deployment incentives of CCS technologies in general

c) Enhanced deployment: current levels of global R\&D funding + 10 times current levels of deployment incentives of CCS technologies in general

d) Enhanced R\&D\& deployment: 10 times current levels of global R\&D funding +10 times current levels of deployment incentives of CCS technologies in general.

I used the Integrated Environmental Control Model as a basis to identify the most costly capital and O\&M components for post-combustion capture systems. The significant oxy-combustion components were distinguished during pilot interviews. The objective of this approach was to identify the potential impacts of increased $R \& D$ and/or demonstration on the various cost components associated with $\mathrm{CO}_{2}$ capture.

Table 3: Capital and O\&M Components evaluated for post-combustion and oxy-combustion technologies.

\begin{tabular}{|l|l|}
\hline \multicolumn{2}{|c|}{ Post-Combustion } \\
\hline Capital Components & O\&M Components \\
\hline Direct Contact Cooler & Sorbent \\
$\mathrm{CO}_{2}$ Absorber Vessel & Electricity \\
Sorbent Regenerator & Steam \\
Drying \& Compression & \\
General Facilities & \\
\hline
\end{tabular}

\begin{tabular}{|l|l|}
\hline \multicolumn{2}{|c|}{ Oxy-Combustion } \\
\hline Capital Components & O\&M Components \\
\hline Air Separation Unit & General O\&M \\
Combustor & \\
Flue Gas Clean Up & \\
\hline
\end{tabular}

The experts, using a scale that ranged from 1 to 5 ( 5 = "increase," 4 = "remain the same," 3 = "decrease slightly," 2 = "decrease moderately," 1 = "decrease significantly"), were asked to assess how the four R\&D and deployment scenarios might impact the costs of each capture 
system's capital and O\&M components. In a few cases, the experts preferred to aggregate the components under the general categories of capital and O\&M costs.

Judging from Table 4a-d, the experts indicated that most of the cost components for amine systems should decrease at least slightly by 2030 even under current RD\&D trends (scenario "A"). They agree unanimously that significant decreases in costs will not occur without more R\&D and deployment incentives. Juxtaposing scenario " $\mathrm{B}$ " and scenario " $\mathrm{C}$ " reveals that more experts think deployment incentives alone can lead to moderate to significant cost reductions, especially with regard to the absorber vessel and solvent regenerator. This result is likely tied to their general view that the chemical processes of amine systems are well understood, so significant cost reductions will materialize with experience and learning through demonstration. The impact of deployment incentives, according to one expert, is timing: "[Deployment] will drive down costs faster - that is the biggest thing, the speed of when these technologies will be available...The decreases will start happening as soon as we get large scale units in operation, and you'll get the first ones up well before 2020." Scenario "D” produced even greater optimism for moderate to significant cost reductions in the absorber vessel, solvent regenerator, drying and compression unit, and steam and electricity consumption. A few experts are skeptical that significant reductions in steam consumption are achievable, reasoning that amines have already reached their potential.

Increases in sorbent costs are not out of the question. Four experts believe costs could increase slightly in 2030 due to greater demand coupled with the use of more complex amines, but they do not agree on which scenarios trigger cost premiums. Two experts predict that scenario "A" alone could trigger cost premiums due to lack of $R \& D$, while two others anticipate the opposite effect: more R\&D alone will improve the chemistry of the solvents and thereby 
contribute to a premium in similar fashion to advanced amines today. The issue then surrounds

the economic trade-off between increased material costs and reduced steam requirement.

Table 4a-d. Potential cost reductions by 2030: Amine-based capture systems

\begin{tabular}{|c|c|c|c|c|c|c|c|c|c|}
\hline \multirow{2}{*}{ Scenario A: Current Trends } & \multicolumn{9}{|c|}{ Number of respondents saying cost will } \\
\hline & Decrease significantly & & Decrease moderately & & Decrease slightly & & Remain the same & & Increase \\
\hline \multicolumn{10}{|l|}{ Capital cost compenents } \\
\hline Direct contact cooler & & & 2 & 1 & 5 & & 4 & 1 & \\
\hline $\mathrm{CO}_{2}$ absorber vessel & sis & $\overline{\mid I T i}$ & 2 & 1 & 8 & (1ii) & 2 & . & ce \\
\hline Sorbent regenerator & & & 2 & 1 & 7 & (ii) & 3 & & c. \\
\hline Drying \& compression unit & 6 & (iii) & 2 & 1 & 6 & (IIi) & 4 & & 6 \\
\hline General facilities & & & 2 & 1 & 7 & & 3 & & \\
\hline \multirow{2}{*}{\multicolumn{10}{|c|}{ O\&M cost components }} \\
\hline & & & & & & & & & \\
\hline Sorbent & C & (10) & 2 & 1 & 8 & (1) & (1) & & 2 \\
\hline Electricity & 6 & (IIi) & 2 & 1 & 7 & (II) & 3 & & s. \\
\hline Steam & 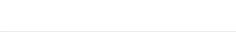 & (10) & 3 & 1 & 7 & (II) & 2 & & . \\
\hline
\end{tabular}

\begin{tabular}{|c|c|c|c|c|c|c|c|c|}
\hline \multirow[t]{2}{*}{ Scenario B: Enhanced R\&D } & \multicolumn{8}{|c|}{ Number of respondents saying cost will } \\
\hline & Decrease significantly & Decrease moderately & & Decrease slightly & & Remain the same & & Increase \\
\hline \multicolumn{9}{|l|}{ Capital cost compenents } \\
\hline Direct contact cooler & & 5 & 1 & 5 & & 1 & 1 & \\
\hline $\mathrm{CO}_{2}$ absorber vessel & 2 & 4 & 1 & 5 & & 1 & & \\
\hline Sorbent regenerator & 1 & 6 & 1 & 5 & & & & \\
\hline Drying \& compression unit & & 8 & 1 & 3 & & 1 & & \\
\hline General facilities & & 5 & 1 & 5 & & 2 & & \\
\hline \multicolumn{9}{|l|}{ O\&M cost components } \\
\hline Sorbent & & 9 & & 1 & 1 & 1 & & 1 \\
\hline Electricity & & 9 & & 2 & & 2 & & \\
\hline Steam & 1 & 10 & & 1 & & 1 & & \\
\hline
\end{tabular}

\begin{tabular}{|c|c|c|c|c|c|c|}
\hline \multicolumn{2}{|c|}{ Scenario C: Enhanced Deployment } & \multicolumn{4}{|c|}{ Number of respondents saying cost will } & \multirow[b]{2}{*}{ Increase } \\
\hline & Decrease significantly & Decrease moderately & Decrease slightly & Remain the same & & \\
\hline \multicolumn{7}{|l|}{ Capital cost compenents } \\
\hline Direct contact cooler & 1 & 6 & 5 & & 1 & \\
\hline $\mathrm{CO}_{2}$ absorber vessel & 2 & 9 & 1 & 1 & & \\
\hline Sorbent regenerator & 1 & 11 & 1 & & & \\
\hline Drying \& compression unit & 2 & 8 & 2 & 1 & & \\
\hline General facilities & 1 & 7 & 3 & 2 & & \\
\hline \multirow{2}{*}{\multicolumn{7}{|c|}{ O\&M cost components }} \\
\hline & & & & & & \\
\hline Sorbent & 2 & 7 & 2 & 2 & & \\
\hline Electricity & 2 & 7 & 2 & 2 & & \\
\hline Steam & 2 & 8 & 2 & 1 & & \\
\hline
\end{tabular}

\begin{tabular}{|c|c|c|c|c|c|c|}
\hline Scenario D: Enhanced R\&D & Deployment & Number 0 & espondents sayin & ost will & & \\
\hline & Decrease significantly & Decrease moderately & Decrease slightly & Remain the same & & Increase \\
\hline Capital cost compenents & & & & & & \\
\hline Direct contact cooler & 2 & 5 & 5 & & 1 & \\
\hline $\mathrm{CO}_{2}$ absorber vessel & 5 & 6 & 1 & 1 & & \\
\hline Sorbent regenerator & 4 & 8 & 1 & & & \\
\hline Drying \& compression unit & 6 & 6 & & 1 & & \\
\hline General facilities & 4 & 4 & 3 & 2 & & \\
\hline O\&M cost components & & & & & & \\
\hline Sorbent & 4 & 5 & 1 & 1 & & 2 \\
\hline Electricity & 6 & 4 & 2 & 1 & & \\
\hline Steam & 7 & 4 & 2 & & & \\
\hline
\end{tabular}


While all thirteen experts were prepared to assess the cost trends for amine-based system components, three declined to comment with regard to chilled ammonia due to the lack of and sensitivity of information. One additional expert declined comment on scenario "C" because of uncertainty in deployment effects. Assessing the changes in component costs for chilled ammonia by 2030 was particularly difficult because estimates in costs are highly uncertain (and proprietary) even today. Thus, the results for scenarios "B", "C", and "D" should be interpreted with respect to scenario "A", and not as absolute cost reductions.

Similar to the amine results, the experts unanimously agree that significant cost reductions are not obtainable under current levels of $R \& D$ and deployment incentives (Table 5ad). The responses are mixed concerning the isolated effects of $R \& D$ and deployment incentives (scenario "B" and "C"). While moderate to significant effects occur more frequently compared to scenario " $\mathrm{A}$ ", there is no consensus that scenario " $\mathrm{C}$ " will yield greater benefits than scenario "B"- as observed in the amine section. This suggests that chilled ammonia still has greater research needs apart from demonstration. One expert provided a brief explanation supporting this claim: "The absorber and regenerator are both integrally linked to chemistry. So as they learn more about the chemistry...the costs will go down."

The wider distribution of results, compared to amines, is perhaps reflective of the greater uncertainty related to chilled ammonia costs and performance relative to amine systems. Some increases in costs are observable, attributed to continual changes to improve the design of the modules and historical trends that show cost increases in the initial stages of emerging technologies (Rubin, 2007). One expert, however, thinks that the industry will see these higher costs in the next 5 years, implying that potential cost reductions should be available by 2030 . 
Table 5 a-d: Potential trends in cost reductions by 2030: Chilled Ammonia Process

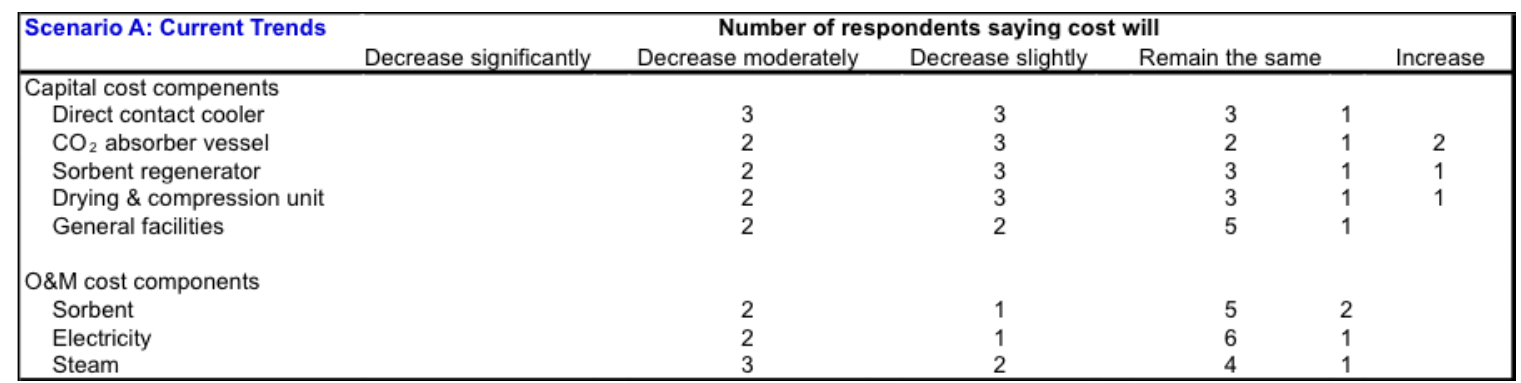

\begin{tabular}{|c|c|c|c|c|c|c|c|c|c|}
\hline \multirow[t]{2}{*}{ Scenario B: Enhanced R\&D } & \multicolumn{9}{|c|}{ Number of respondents saying cost will } \\
\hline & \multicolumn{2}{|l|}{ Decrease significantly } & \multicolumn{2}{|l|}{ Decrease moderately } & \multirow[t]{2}{*}{ Decrease slightly } & \multicolumn{3}{|c|}{ Remain the same } & \multirow[t]{2}{*}{ Increase } \\
\hline Capital cost compenents & & & & & & & & & \\
\hline Direct contact cooler & 2 & & 2 & 1 & 4 & (7) & 1 & 5 & \\
\hline $\mathrm{CO}_{2}$ absorber vessel & 1 & 8 & 3 & 1 & 2 & (i) & 2 & (i) & 1 \\
\hline Sorbent regenerator & 1 & 8 & 4 & 1 & 2 & (ii) & 1 & $\sqrt{10}$ & 1 \\
\hline Drying \& compression unit & 1 & & 4 & 1 & 3 & (ii) & 1 & (i) & \\
\hline General facilities & 1 & & 1 & 1 & 4 & (1) & 3 & & \\
\hline O\&M cost components & & & & 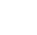 & & & & 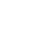 & \\
\hline Sorbent & 1 & & 1 & 1 & $?$ & & 4 & & \\
\hline Electricity & 1 & 0 & 1 & 1 & 2 & 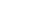 & 4 & 1 & \\
\hline Electricity & 1 & (i) & 2 & 1 & 4 & (i) & 2 & & \\
\hline Steam & 2 & 8 & 3 & 1 & 3 & 01 & 1 & 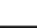 & Dif \\
\hline
\end{tabular}

\begin{tabular}{|c|c|c|c|c|c|c|c|c|c|}
\hline \multicolumn{2}{|c|}{ Scenario C: Enhanced Deployment } & \multicolumn{6}{|c|}{ Number of respondents saying cost will } & & \multirow[b]{2}{*}{ Increase } \\
\hline & Decrease significantly & & Decrease moderately & & Decrease slightly & & Remain the same & & \\
\hline \multicolumn{10}{|l|}{ Capital cost compenents } \\
\hline Direct contact cooler & 2 & & 4 & & 1 & 1 & 1 & & \\
\hline $\mathrm{CO}_{2}$ absorber vessel & 1 & (1) & 5 & (1) & 2 & (1) & (1) & 9 & 1 \\
\hline Sorbent regenerator & 1 & & 4 & & 3 & i] & i) & & 1 \\
\hline Drying \& compression unit & 1 & & 5 & & 1 & (6) & 2 & & \\
\hline General facilities & 1 & & 3 & & 2 & $\|$ & 3 & & \\
\hline \multicolumn{10}{|l|}{ O\&M cost components } \\
\hline Sorbent & 1 & & 2 & & 4 & 0 & 2 & 7 & \\
\hline Electricity & 1 & & 1 & & 5 & [i] & 2 & & \\
\hline Steam & 2 & 5 & 2 & (1) & 5 & 8 & 0 & 71 & 0 \\
\hline
\end{tabular}

\begin{tabular}{|c|c|c|c|c|c|c|c|c|c|}
\hline \multicolumn{2}{|c|}{ Scenario D: Enhanced R\&D \& Deployment } & \multicolumn{7}{|c|}{ Number of respondents saying cost will } & \multirow[b]{2}{*}{ Increase } \\
\hline & Decrease significantly & & Decrease moderately & & Decrease slightly & & Remain the same & & \\
\hline \multicolumn{10}{|l|}{ Capital cost compenents } \\
\hline Direct contact cooler & 5 & (ii) & 2 & & 3 & (ii) & is & (i) & \\
\hline $\mathrm{CO}_{2}$ absorber vessel & 3 & 1 & 4 & & 1 & (1) & & & 1 \\
\hline Sorbent regenerator & 4 & 1 & 2 & & 2 & (i) & 9 & & 1 \\
\hline Drying \& compression unit & 4 & 1 & 4 & (i) & 0 & (1i) & 1 & (i) & \\
\hline General facilities & 4 & ii & 1 & (9) & 3 & 8 & 2 & & \\
\hline \multicolumn{10}{|l|}{ O\&M cost components } \\
\hline Sorbent & 4 & (1) & 1 & & 3 & (i) & 2 & & \\
\hline Electricity & 3 & 1 & 1 & & 3 & & 2 & i & \\
\hline Steam & 5 & 1 & 1 & i) & 3 & & 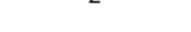 & & \\
\hline
\end{tabular}

All thirteen experts evaluated potential cost trends for oxy-combustion technology; one declined to comment with regard to O\&M. Again, the responses indicate that significant decreases will not occur without further funding in R\&D and deployment. Although Tables $6 b$ 
and $6 \mathrm{c}$ show no consensus on whether $\mathrm{R} \& \mathrm{D}$ or deployment incentives alone will yield greater benefits, the general view according to the verbal responses stresses the importance of R\&D because of the relative immaturity of oxy-combustion. In scenario "C", we observe that deployment incentives alone may yield moderate to significant cost reductions in all four components, but particularly for the combustor. One expert explained that from a retrofit standpoint, there is little that $\mathrm{R} \& \mathrm{D}$ can do to improve the combustor, implying that demonstration is crucial to gaining better understanding of boiler design.

Half of the experts anticipate at least moderate reductions in the air separation unit even under scenario "A". The consensus is almost unanimous for significant reductions in the ASU under scenario " $\mathrm{D}$ ". The assumption is that a breakthrough in membrane technologies is achievable with aggressive $\mathrm{R} \& \mathrm{D}$ and deployment incentives, a result that could lead to substantial decreases in capital and O\&M costs. As one expert put it, "ITM is the designer technology that everyone is looking to: the holy grail of air separation." The lone expert who deviated from the norm remains skeptical about this discovery, stating that the industry has been chasing a breakthrough for many years with little success. There is agreement that potential improvements in the flue gas clean-up and general $\mathrm{O} \& \mathrm{M}$ (which includes air separation and $\mathrm{CO}_{2}$ product clean-up) are achievable under the aggressive policy scenarios. One expert pointed out that the flue gas clean-up equipment is still in early stages of development, so potential improvements should occur under enhanced RD\&D. Across all three technologies, the synergistic effects of R\&D and deployment incentives in scenario " $D$ " generate the most responses corresponding to significant cost reductions. 
Table 6 a-d: Potential trends in cost reductions by 2030: Oxy-Combustion

\begin{tabular}{|c|c|c|c|c|c|c|c|c|c|}
\hline \multirow{2}{*}{ Scenario A: Current Trends } & \multicolumn{9}{|c|}{ Number of respondents saying cost will } \\
\hline & Decrease significantly & & Decrease moderately & & Decrease slightly & & Remain the same & & Increase \\
\hline \multicolumn{10}{|l|}{ Capital cost compenents } \\
\hline Air separation & (i) & (16; & 4 & $(6)$ & 2 & lij & 6 & 1 & (6) \\
\hline Combustor & & & 1 & & 4 & & 7 & 1 & \\
\hline Flue gas clean-up & (1) & (15) & 2 & 5 & 3 & & 8 & & (if) \\
\hline O\&M costs & & & 3 & & 3 & & 6 & & \\
\hline
\end{tabular}

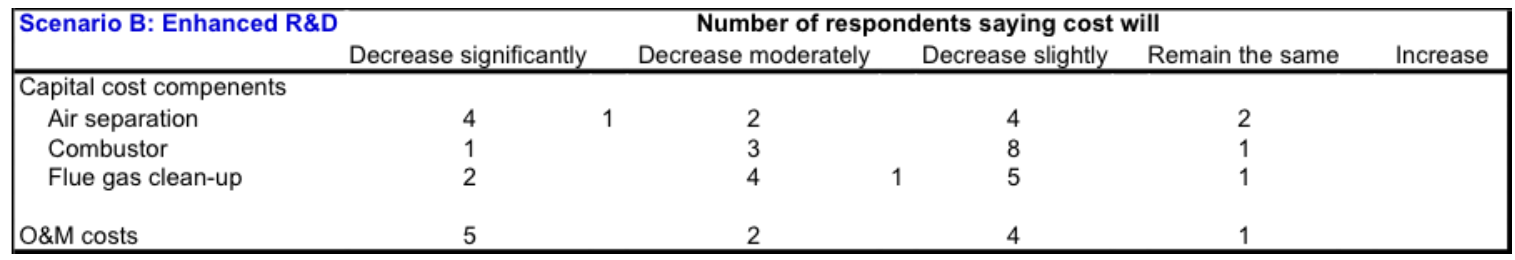

\begin{tabular}{|c|c|c|c|c|c|c|c|c|}
\hline \multicolumn{2}{|c|}{ Scenario C: Enhanced Deployment } & \multicolumn{6}{|c|}{ Number of respondents saying cost will } & \multirow[b]{2}{*}{ Increase } \\
\hline & Decrease significantly & & Decrease moderately & & Decrease slightly & Remain the same & & \\
\hline \multicolumn{9}{|c|}{ Capital cost compenents } \\
\hline Air separation & 5 & 1 & 3 & & 3 & 1 & & \\
\hline Combustor & 2 & & 7 & & 3 & 1 & & \\
\hline Flue gas clean-up & 4 & & 4 & 1 & 3 & 1 & & \\
\hline O\&M costs & 3 & 1 & 2 & & 6 & & & \\
\hline
\end{tabular}

\begin{tabular}{|c|c|c|c|c|c|c|c|c|}
\hline \multicolumn{2}{|c|}{ Scenario D: Enhanced R\&D \& Deployment } & \multicolumn{6}{|c|}{ Number of respondents saying cost will } & \multirow[b]{2}{*}{ Increase } \\
\hline & Decrease significantly & & Decrease moderately & & Decrease slightly & Remain the same & & \\
\hline \multicolumn{9}{|c|}{ Capital cost compenents } \\
\hline Air separation & 12 & & (1) & & & 1 & & \\
\hline Combustor & 4 & & 7 & & 1 & 1 & & \\
\hline Flue gas clean-up & 7 & & 4 & & 1 & 1 & & \\
\hline O\&M costs & 7 & & 2 & & 3 & & & \\
\hline
\end{tabular}

\section{PROBABILISTIC JUDGMENTS ON PARASITIC LOAD}

Stating the assumptions of a generic pulverized coal-fired power plant outlined in Table

7, I asked the experts to provide ranges and best estimates of the typical parasitic load, or energy

penalty, they believe will be imposed in 2030 due to retrofitting a coal plant with $\mathrm{CO}_{2}$ capture

systems. For this section, responses were recorded for only policy scenarios "A" and "D".

Eleven experts provided their probabilistic judgments for amine systems and only eight 
responded for both chilled ammonia and oxy-fuel. Figure $3 \mathrm{a}$ through $3 \mathrm{f}$ display results for amine systems, chilled ammonia process, and oxy-combustion.

Table 7. Assumptions of a generic pulverized coal power plant

- 20 years old

- 500 MW capacity

- $\quad 35 \%$ efficiency (HHV)

- Bituminous coal: Pittsburgh \#8

- Sub-critical boiler

- WFGD installed

- SCR installed

- PM control: Cool-side ESP

- Fully paid off

- $\quad 90 \%$ capture

Estimated ranges of the parasitic load are broad. For example, for oxy-combustion, there is more than a factor of 6 difference between the most pessimistic energy penalty reported under the aggressive RD\&D scenario (the "highest 95\% confidence" limit of 55\%) and the most optimistic energy penalty reported under the current trend scenario (the "lowest $95 \%$ confidence limit of $8 \%$ ). Similarly broad ranges were given for energy penalties of amine and chilled ammonia systems. Note that the distributions of the upper limit, best estimate, and lower limit narrow significantly under the aggressive policy scenario for all three technologies; the higher estimates are shaved off, reflecting learning and increased optimization of second or third generation plants. Reasons for amine improvements included learning by doing, better integration, design optimization and the potential for advanced amines to reduce the power requirement. The higher estimates for oxy-combustion are specifically a function of the current state of air separation technology. For oxy-combustion, experts 1, 2, 5, and 10 assume that aggressive RD\&D can accomplish major reductions in air separation costs, and they stress that 
energy penalty decreases only occur in the RD\&D case assuming a breakthrough in air separation technology. Even assuming breakthroughs in air separation, however, the estimates still remain uncertain in the RD\&D scenario and two experts do not see decreases occurring below $30 \%$. Interestingly, the ranges for chilled ammonia contain the narrowest distributions of the three technologies, which may indicate a relatively lower level of uncertainty with respect to chilled ammonia's expected performance. One caveat is that chilled ammonia, according to some of the experts, is only practical for colder climates, which limits its application. Note that the sample size is relatively small and the actual outcome may not be the average of all expert opinions; some experts may have better technical information or better intuition in making probabilistic judgments.

Table 8 summarizes the median value of the experts' best estimates for 2030 energy penalties incurred by generic PC power plants. The observable energy penalty reductions due to aggressive $\mathrm{RD} \& \mathrm{D}$ are $3,3.25$, and 5 percentage points for amines, chilled ammonia, and oxycombustion, respectively. Best estimates for chilled ammonia display the most promising results and the narrowest $95 \%$ confidence intervals.

Figure 3a-b. Reference case and aggressive RD\&D case for amine capture system energy penalty estimates in 2030 .

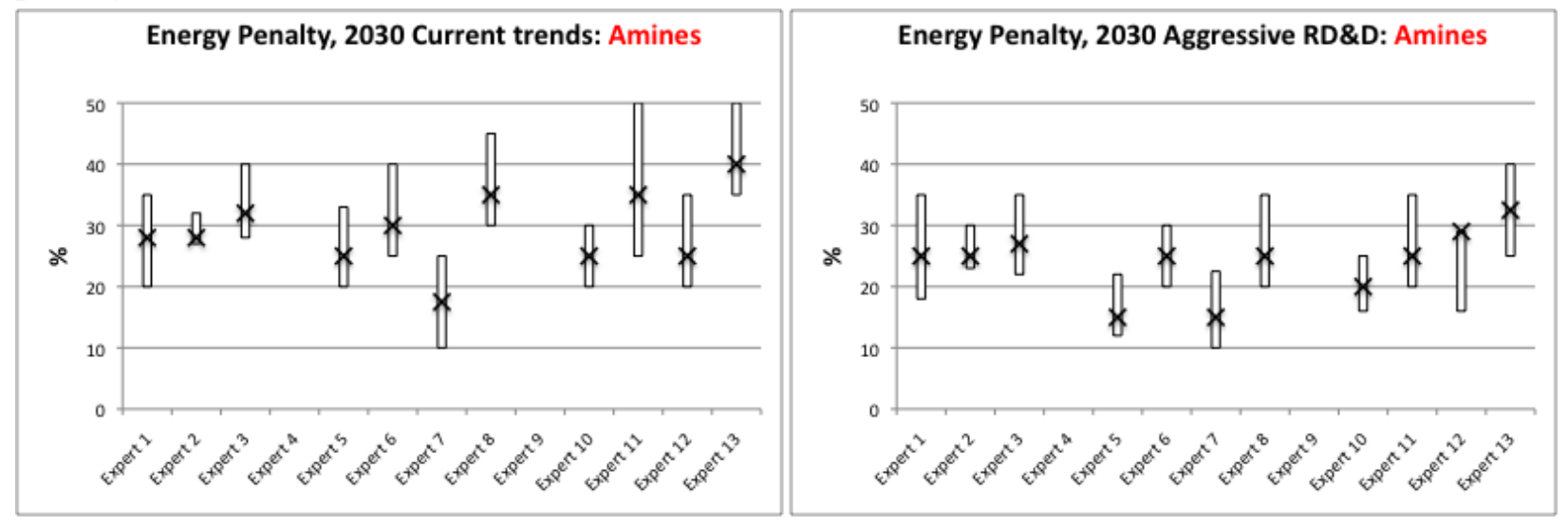


Figure 3c-d. Reference case and aggressive RD\&D case for chilled ammonia process energy penalty estimates in 2030 .
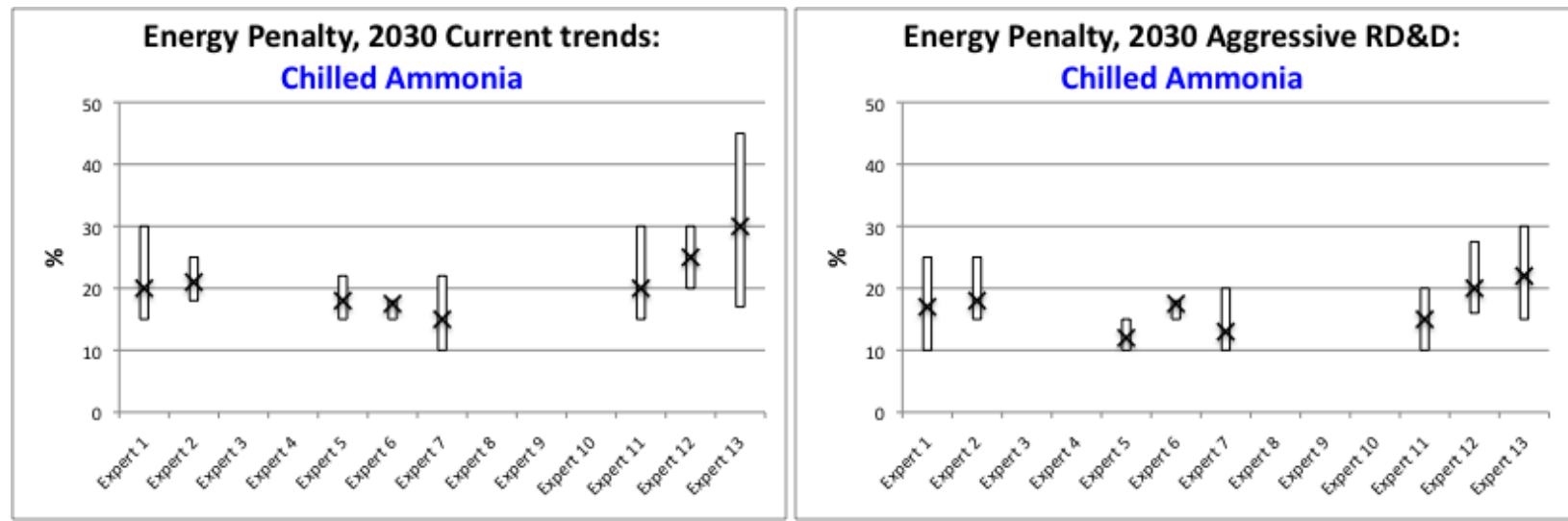

Figure 3e-d. Reference case and aggressive RD\&D case for oxy-combustion energy penalty estimates in 2030.

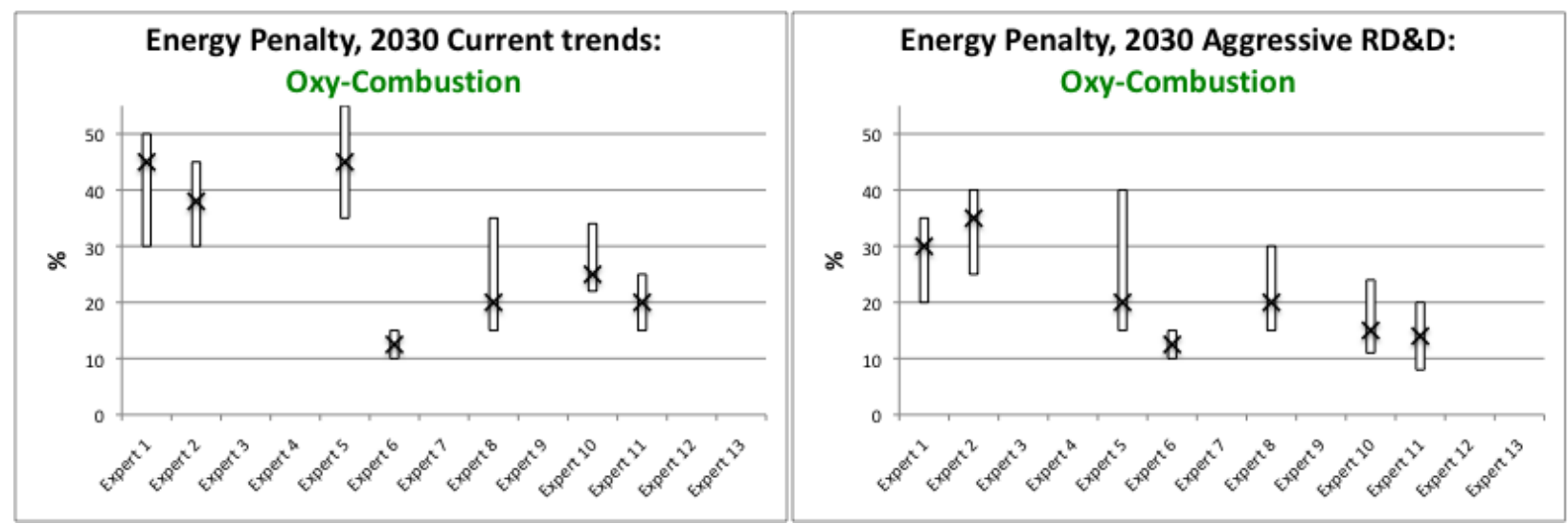

Table 8. Median estimates for energy penalties in 2030

\begin{tabular}{|l|c|c|}
\hline \multirow{2}{*}{ Amines } & \multicolumn{2}{c|}{ Median estimates for 2030 Energy penalties } \\
\cline { 2 - 3 } & Current Trends & Aggressive RD\&D Case \\
\hline Chilled Ammonia & $28 \%$ & $25 \%(-3)$ \\
\hline Oxy-combustion & $20 \%$ & $16.75 \%(-3.25)$ \\
\hline
\end{tabular}




\section{DISCUSSION}

Early commercial retrofits will require very specific conditions. Land availability and location will determine a site's suitability for retrofit, and newer units with high thermal efficiencies and best available control technologies will provide optimal performance parameters for $\mathrm{CO}_{2}$ capture systems. Expert judgments for energy penalty estimates in 2030 under current RD\&D trends exhibit considerable uncertainty for all three technologies, suggesting that retrofitted plants will incur relatively higher energy penalties without significant increases in $\mathrm{RD} \& \mathrm{D}$ funding. This suggestion is confirmed by the expert opinions under the aggressive RD\&D policy scenario: the ranges of estimates narrow significantly and the median best estimates decrease at least three percentage points for each technology (Table 8). Improvements in amine system energy penalties exhibit the least potential, which is expected considering the higher maturity level of amines. The emphasis for driving down the energy penalty for amines is on deployment and advanced solvents. The expert estimates for chilled ammonia process exhibit the most promise for lowering the energy penalty below $20 \%$ : the median for best estimates are $20 \%$ and $16.75 \%$ for the reference case and aggressive RD\&D case, respectively. Further research in the chemical processes of chilled ammonia reacting with coal-derived flue gas was the primary emphasis for achieving these targets. The limiting factor for chilled ammonia is location: plants close to populations or located in warm climate regions may not be suitable for chilled ammonia retrofits. Expert perceptions of oxy-combustion energy penalty estimates contain the greatest uncertainty, attributable to oxy-fuel hinging directly on achieving significant improvements in air separation technology. Another theme consistent throughout the interviews is that oxy-combustion is a technology more suited for new plant constructions. Existing units 
are not designed to combust coal with pure oxygen, so the challenges facing oxy-fuel retrofits may render it a green-field or brown-field repowering technology.

\section{COST MODEL}

To obtain an idea of the benefits that correspond with reductions in the energy penalty for amine-based retrofits, I developed a cost model using cost and performance parameters obtained from the Integrated Environmental Control Model (IECM, 2009). The assumptions of a 500MW (gross) unit from Table 7 were applied as inputs to establish the plant parameters in the IECM. The capital and variable O\&M costs attributed to the $\mathrm{CO} 2$ capture plant were isolated from the base plant and the assumed replacement power cost was \$100/MWh.

The IECM provides a detailed account of the costs and emissions resulting from an amine-based retrofit. The cost model isolates the capital and O\&M costs -fixed and variable O\&M (non-electricity) - and holds them constant in all calculations of $\mathrm{CO}_{2}$ avoidance costs. O\&M costs associated with electricity change as a function of the energy penalty, thereby increasing the avoidance cost with higher penalties and decreasing the avoidance cost with lower penalties. Recall that energy penalties of $28 \%$ and $25 \%$ represent the "best estimate" median values obtained from the respondents under the current trend scenario and aggressive policy scenario for amine-based capture systems, respectively. In other words, the indication from this sample of experts is a 3-percentage point energy penalty decrease contingent upon more RD\&D spending. Assume that this is the "reference case" scenario. In the "best case" scenario, we should expect a decrease of 8-percentage points to $20 \%$, which represents the median response for the lower 95\% confidence interval under the aggressive policy scenario. 
Results from the model indicate that under the reference case (energy penalty declines from $28 \%$ to $20 \%$ ), the improvement equates to a $10.7 \%$ decrease in annual operating costs associated with electricity. In the best case scenario (energy penalty declines from $28 \%$ to $20 \%$ ), the savings increase to $28.6 \%$ and the $\mathrm{CO}_{2}$ avoidance cost decreases $16.3 \%$ from $\$ 55$ to $\$ 46$ per ton of $\mathrm{CO}_{2}$ (constant 2006 dollar). Figure 4 illustrates how avoidance costs change as a function of the energy penalty. A sensitivity analysis, depicted in figure 5, shows that replacement power has a strong impact on avoidance costs. For example, a power plant that incurs a $25 \%$ energy penalty will absorb a $\mathrm{CO}_{2}$ capture cost of roughly $\$ 52 /$ ton if replacement power is priced at $\$ 100 / \mathrm{MWh}$. If the electricity costs increase $50 \%$ to $\$ 150 / \mathrm{MWh}$, the resulting increase equates to roughly $\$ 66 /$ ton, an increase of $27 \%$.

Figure 4: $\mathrm{CO}_{2}$ avoidance cost as a function of energy penalty (amine capture system), assuming \$100/MWh for replacement power.

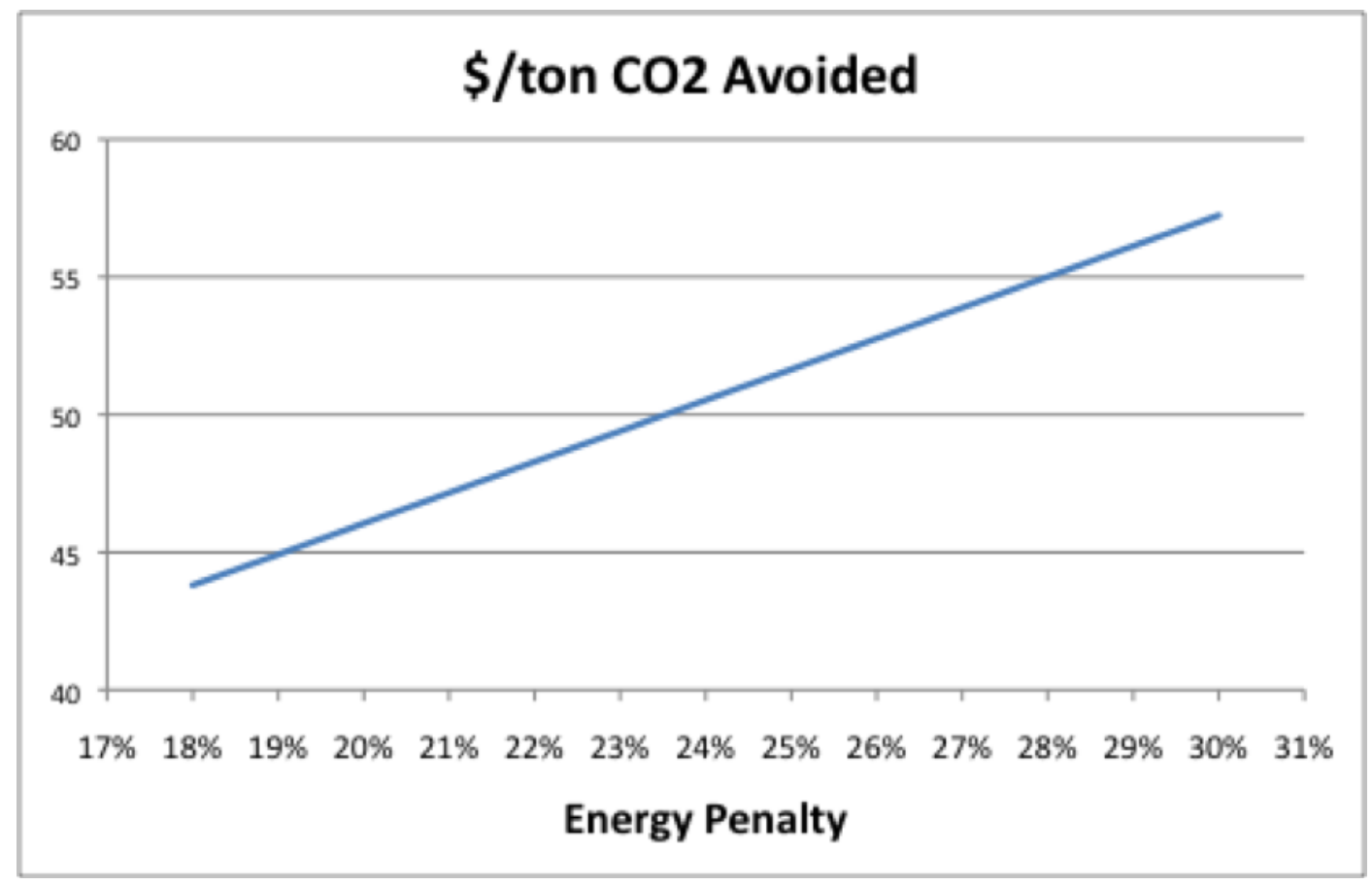


Figure 5: Sensitivity analysis, varying replacement power costs.

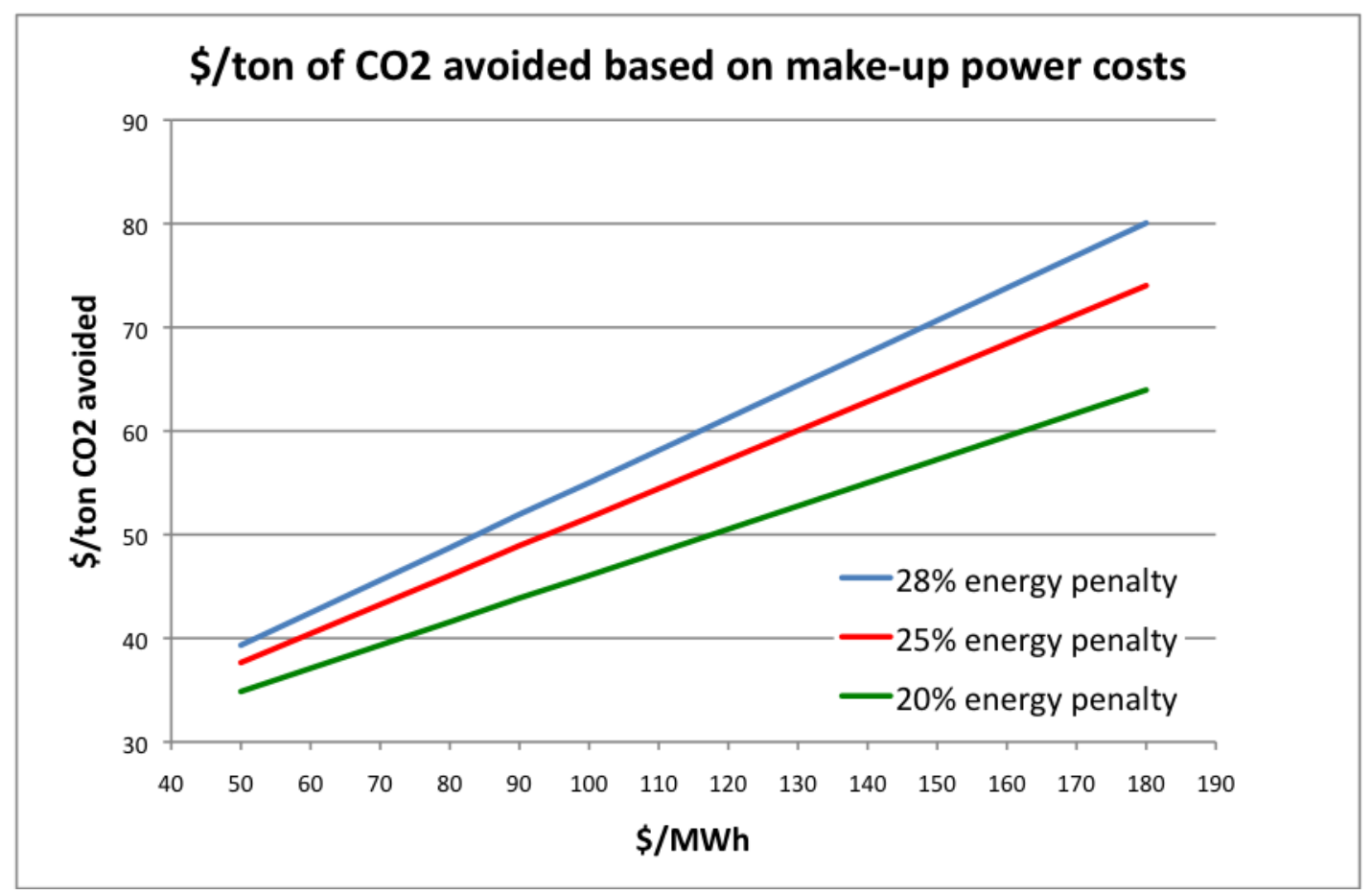

\section{COST-BENEFIT ANALYSIS}

The cost model identifies the capital and operating costs associated with retrofitting a generic 500-MW power plant with an amine-based $\mathrm{CO}_{2}$ capture system. I calibrated the model to vary the annual operating costs as a function of the energy penalty. A cost-benefit approach helps translate these cost savings into a policy framework. Although the questionnaire did not specify the dollar amount associated with "10x R\&D and deployment," I assume a U.S. government investment of $\$ 10$ billion spread across 10 years (2020-2029) as a proxy for an aggressive RD\&D scenario. This value is consistent with recent studies that suggest CCS RD\&D will require an unprecedented \$10 billion across 10 years (EPRI, 2008 and MIT, 2007). The benefits of RD\&D investments are defined in terms of avoided costs, whereby a retrofitted 
unit will incur a lower energy penalty and avoid additional operating costs had the RD\&D investment not taken place. To define these benefits, I applied the best case scenario results from the cost model and took the annual difference in $\mathrm{CO}_{2}$ avoidance costs between a unit with a $28 \%$ energy penalty and the same unit with a $20 \%$ energy penalty. The assumed life-span of a retrofitted unit is assumed to be 20 years. To account for learning and experience, a unit with a $28 \%$ energy penalty in 2030 experiences straight-line energy penalty reductions to $25 \%$ by 2049 . Thus, this cost-benefit analysis compares investment costs and annual savings over 30 years, with \$1 billion annual investment costs occurring from 2020 to 2029 and benefits (avoided costs) occurring for 20 years from 2030 to 2049 . The present value of costs are represented in the following equation:

$\sum_{21}^{30} \$ 1$ billion $(1+r)^{t-1}=$ present value of Costs

The present value of benefits are represented as:

$$
\begin{aligned}
& \text { Let } x=\$ / \text { ton } \mathrm{CO}_{2[\text { retrofitunitundercurrent } R \& D \text { trend }]} \\
& \text { Let } y=\$ / \text { ton } C O_{2[\text { retrofitunitunderenhanced } R \& D \text { policy }]} \\
& \sum_{11}^{30} \frac{\left(x_{t}-y_{t}\right)}{(1+r)^{t}} \times \frac{\text { tons } C_{2} \text { avoided }}{\text { year }}=\text { present value of Benefits }
\end{aligned}
$$

The present value of benefits represents the avoided costs for one 500-MW retrofitted unit at $20 \%$ energy penalty versus a $28 \%$ energy penalty. Dividing the present value of costs by the present value of benefits yields the total number of retrofitted units needed to break-even with the initial investment in RD\&D. The results in Figure 6 show the required number of 
retrofits using discount rates from 4 to $6 \%$. With a $4 \%$ discount rate, 148 units would need to be retrofitted in order to justify the RD\&D investment. This corresponds to roughly $75 \mathrm{GW}$ of current coal generated capacity, almost $25 \%$ of the existing fleet.

\section{Figure 6}

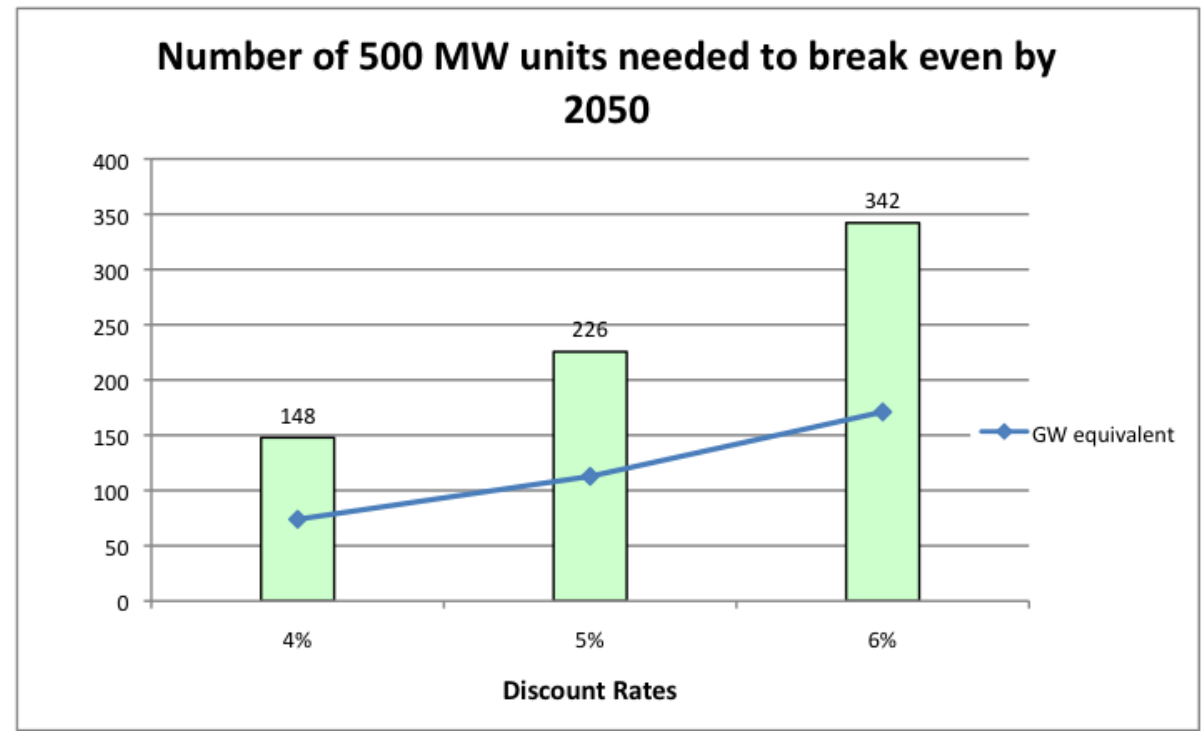

\section{CONCLUSION}

This study frames the levels of uncertainty in the energy penalty for amine-based, chilled ammonia-based, and oxy-combustion capture systems. Results from the cost model indicate that with aggressive $\mathrm{RD} \& \mathrm{D}$, the best case scenario for amine-based energy penalty reductions (from $28 \%$ to $20 \%$ ) equates to electricity and steam consumption savings of $28.6 \%$ and a $19 \%$ reduction in $\mathrm{CO}_{2}$ avoidance costs. The cost-benefit analysis demonstrates that a large number of 500-MW units would need to be retrofitted with amine systems to justify a $\$ 10$ billion RD\&D investment. However, the analysis is limited in that it isolates costs with respect to energy penalty for amine systems. With large expenditures in CCS RD\&D, we would expect to see 
reductions in capital costs and other operating costs (sorbents) that are not captured in this analysis. 


\section{REFERENCES}

Anderson, Sorenand, Richard Newell. (2004). Prospects for carbon capture and storage technologies. Annual review of environment and resources, 29 (1), 109.

Black, Sean, Philippe Paelinck, Fred Kozak, Arlyn Petig, Ed Morris. (2008). Chilled Ammonia Process $\mathrm{CO}_{2}$ Capture. Alstom Paper, retrieved from primary author on January 16, 2009.

Curtright, A. E., et al. (2008). Expert Assessments of future Photovoltaic Technologies. Environmental Science Technologies.

Electric Power Research Institute. (2008). Advanced Coal Power Systems with $\mathrm{CO}_{2}$ Capture: EPRI's Coal Fleet for Tomorrow Vision. EPRI Interim Report, September 2008.

Energy Information Administration. (2009). Annual Energy Outlook 2009. DOE: Washington DC.

Environmental Protection Agency. (2007). eGrid2007 Version 1.1. Retrieved on January 16, 2009, from http://www.epa.gov/cleanenergy/energy-resources/egrid/index.html

Hassel, Bart A., et al. (2008). Oxygen Transport Membrane Based Oxy Combustion for $\mathrm{CO}_{2}$ Capture from Coal Power Plants. PowerPoint presentation. Delivered at the $7^{\text {th }}$ Annual Conference on Carbon Capture and Sequestration, 2008.

IEA Greenhouse Gas R\&D Programme. (2007). $\mathrm{CO}_{2}$ Capture Ready Plant. International Energy Agency, 2007/4, May 2007.

Integrated Environmental Control Model and User Documentation. (2001). Center for Energy and Environmental Studies. Carnegie Mellon University, Pittsburgh, PA. www.iecmonline.com

International Panel on Climate Control. (2005). Carbon Dioxide Capture and Storage. IPCC Special Report.

Krocher, Oliver et al. (2007). Ammonia measurement with a pH electrode in the ammonia/ureaSCR process. Measurement Science and Technology 18/771.

Massachusetts Institute of Technology. (2007). The Future of Coal: Options for a CarbonConstrained World. MIT Report.

National Coal Council. (2007). NCCRB Report, Section One: World Energy and Greenhouse Gas Emissions Context. Retrieved on April 22, 2009 from: www.nationalcoalcouncil.org/Document/NCCRB_June2007.pdf

Pew Center on Global Climate Change. (2009) Coal and Climate Change Facts. Retrieved March 31, 2009, from http://www.pewclimate.org/global-warming-basics/coalfacts.cfm. 
Rubin, Edward S, et al. (2007). Use of experience curves to estimate the future cost of power plants with $\mathrm{CO}_{2}$ Capture. International Journal of Greenhouse Gas Control I: 188-197.

Simbeck, Dale. (2007). $\mathrm{CO}_{2}$ Capture Technologies. PowerPoint presentation. Staff Workshop on Technical Papers for AB1925 Report to the Legislature, Sacramento, CA. Retrieved March 31, 2009 from http://www.docstoc.com/docs/4555189/Staff-Workshop-onTechnical-Papers-for-Report-to-the 